\title{
Investigation of Failure in Main Fuel Pump of an Aeroengine
}

\author{
M. Sujata, M. Madan, S.K. Bhaumik \\ Council of Scientific and Industrial Research (CSIR), National Aerospace Laboratories, \\ Materials Science Division Bangalore 560017
}

\begin{abstract}
There was an accident to a fighter aircraft. Investigation revealed that the accident was caused due to loss of power in the engine as a result of failure in the main fuel pump (MFP). The MFP was multi-plunger type. On dis-assembly, the MFP was found severely damaged and there were fractures in one plunger and four springs. Through systematic metallurgical investigation and analysis, the sequence of events leading to the failure in the MFP was established. The primary failure in the MFP was the fatigue fracture of springs. The fatigue crack initiation could be attributed to pitting corrosion on the surface of the springs. Because of multiple fractures in one of the springs, there was impact load on the corresponding plunger, which resulted in generation of an overload crack. This crack had further propagated progressively by fatigue mechanism culminating in fracture and loss of material from the side wall of the plunger. Subsequently, there was fuel leakage internally in the MFP with the resultant reduction in the fuel delivery pressure. Due to insufficient fuel supply, there was winding down of the engine RPM leading to loss of thrust. After establishing the sequence of failure in the MFP, investigation was carried out to identify the cause for the corrosion on the surface of the springs. It was established that the raw material (wires) used for the manufacture of the springs had developed corrosion pits on the surface due to improper storage.
\end{abstract}

Keywords: Aeroengine; main fuel pump; spring; fatigue; corrosion

\section{Introduction}

The components in an aeroengine always operate under most arduous conditions and the application demands working of the components in tandem. Failure in any of the components leads to catastrophe with resultant loss of the aircraft and also, loss of valuable lives. Aeroengine being a safety critical system, is normally manufactured, serviced and maintained to the highest standards. Yet, aircraft accidents do take place due to engine failures. Failures in aeroengines are more likely the result of a chain of events rather than due to a single cause. Investigation of aeroengine failures is, therefore, complex and challenging [1-2]. 
The components of aeroengines are subjected to cyclic loading during their operational usage. Because of this, the components experience fatigue leading to initiation and propagation of cracks at highly stressed areas. Statistics show that fatigue is the predominant mode of failure in aircraft components and it accounts for nearly $60 \%$ of the total failures [3]. If one considers the failures in engine components alone, the percentage of fatigue failure is still higher.

Generally, the components of aeroengines are designed for safe life with the minimum probability of fatigue cracking during the life span. In spite of this, fatigue failures of the components are common. Fatigue cracks generally initiate at locations of high stress concentrations. Study shows that the stress concentrators are invariably related to defects of various types, introduced mostly inadvertently, at various stages of the life cycle of the components, starting from manufacturing to service retirement [4-5]. Stress concentration also arises because of corrosion during service due to interaction of the components with the operating environment. In these cases, the failure generally does not take place due to loss of substantial amount of material. Instead, the stress concentration arising from the corrosion facilitates premature fatigue crack initiation in the component and its eventual failure by fatigue fracture.

In this paper, investigation of a failure in the main fuel pump of an aeroengine has been reported. The failure had resulted in loss of power in the engine, leading to an accident. Through systematic investigation and analysis, the primary cause of failure in the MFP and the sequence of events that led to the accident were established.

\section{Information}

A fighter aircraft met with an accident during a practice sortie with parallel taxi track overshoot and landing. The pilot had carried out two overshoots during the flight of 22 minutes. During the final circuit while on turn, pilot suddenly felt loss of thrust and observed winding down of the engine RPM. Thereafter, finding no response to the throttle movement, the pilot ejected safely and the aircraft crashed onto the ground. Since the aircraft was flying at low altitude, the impact was not very severe. Also, there was no postaccident fire.

The engine was removed from the aircraft and strip examined. Most of the components of the engine were in good condition. Based on the pilot's 
statement and flight data recorder (FDR) analysis, it was decided to carry out functional test on the main fuel pump (MFP). During the test, the maximum fuel pressure build-up in the pump was recorded to be $15 \mathrm{~kg} / \mathrm{cm}^{2}$, which was significantly less than the required limit of $100 \mathrm{~kg} / \mathrm{cm}^{2}$. On dis-assembly, the MFP was found severely damaged.

\section{Construction and working of MFP}

Schematic of the MFP is shown in Fig.1. The MFP in the present case is multiplunger type and had nine plungers. The plungers are housed in the cavities or chambers of the rotor. For facilitating unobstructed up and down movement, each plunger is assembled in the rotor chamber with a guide and a spring. The plunger heads are crowned and in the assembly, they remain flushed with a swash plate. One end of the swash plate is fixed while the other end is operated by a servo piston. The angular position of the swash plate ensures up and down movement of the plungers when the rotor is on rotation. This facilitates the fuel to enter into the plungers and to deliver to the respective ports. At the bottom of the rotor, a plate having two kidney ports is fixed for the fuel to enter and to exit during each rotation of the rotor.

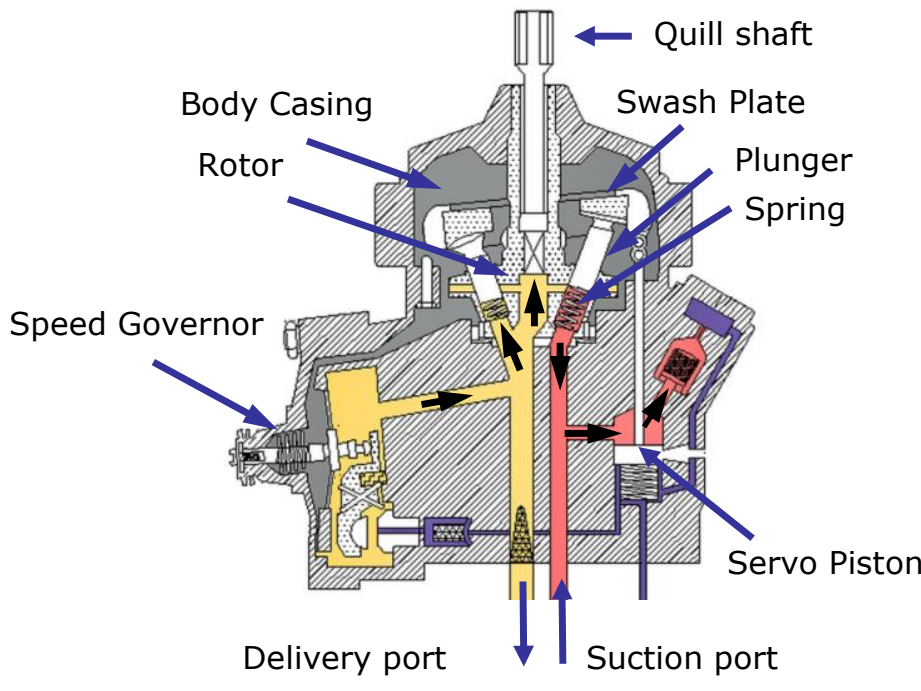

(a)

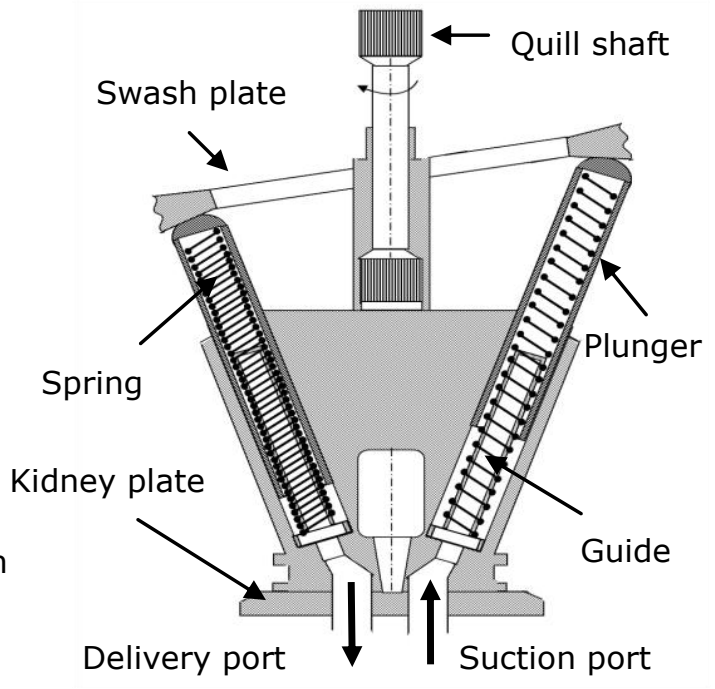

(b)

Figure 1: Schematic of (a) MFP in assembly, and (b) components of MFP 


\section{Observations during dis-assembly of MFP}

After dis-assembly of the swash plate, deep score marks were observed on the outer conical surface of the rotor and the corresponding inner surface of the pump body casing. It was found that two plungers (at cavity No. 3 and 4) were in partially pressed condition and one plunger (at cavity No. 5) was in fully pressed condition. The other six plungers were in normal position. Examination revealed loss of material from the side wall of the plunger that was located at cavity No.3. Later, the fractured part of the plunger was recovered from inside the MFP body casing.

On removal of the plungers from the rotor cavities, four of the springs were found to be broken. These springs were located in the cavity Nos. 3,4,6 and 7. The spring in the cavity No.3 had broken into four pieces while the other three have broken into two pieces. In the cavity No.3, the broken parts of the spring was found entangled and telescoped in. However, the spring in the cavity No. 5 was in tact, where the plunger was found in fully pressed condition. All the spring guides were found undamaged.

\section{Laboratory Investigation and Test Results}

\subsection{Rotor}

The rotor of the MFP is shown in Fig.2(a). Damages were observed on the outer conical surface of the rotor encompassing a circular band, and located close to the bottom. A dig mark resembling an arc was observed on the face of the rotor in the vicinity of cavity No.3 (Fig.2(b)). Also, can be seen is the polishing wear on a sector of the inner surface of the cavity No.3 (Fig.2(c)). This indicated that the body of the plunger No.3 was preferentially in contact with this region of the cavity surface at least for a part of its operation.

There was no distress on the quill shaft of the rotor. The splines on the shaft were found in tact without any damage. Also, there were no evidences which could be suggestive of misalignment in the assembly. 


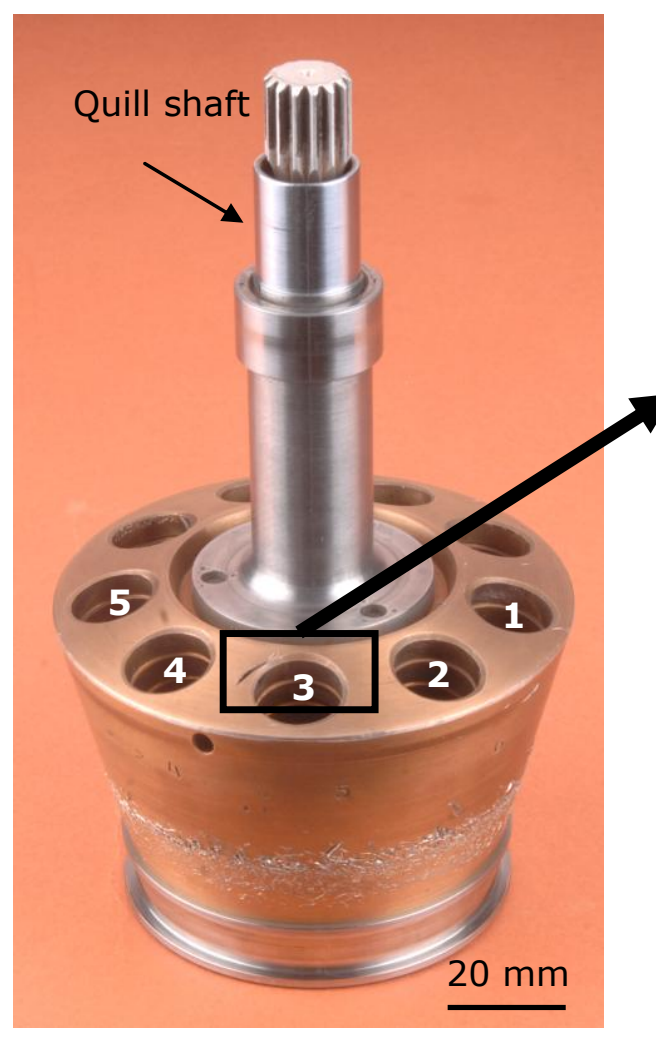

(a)

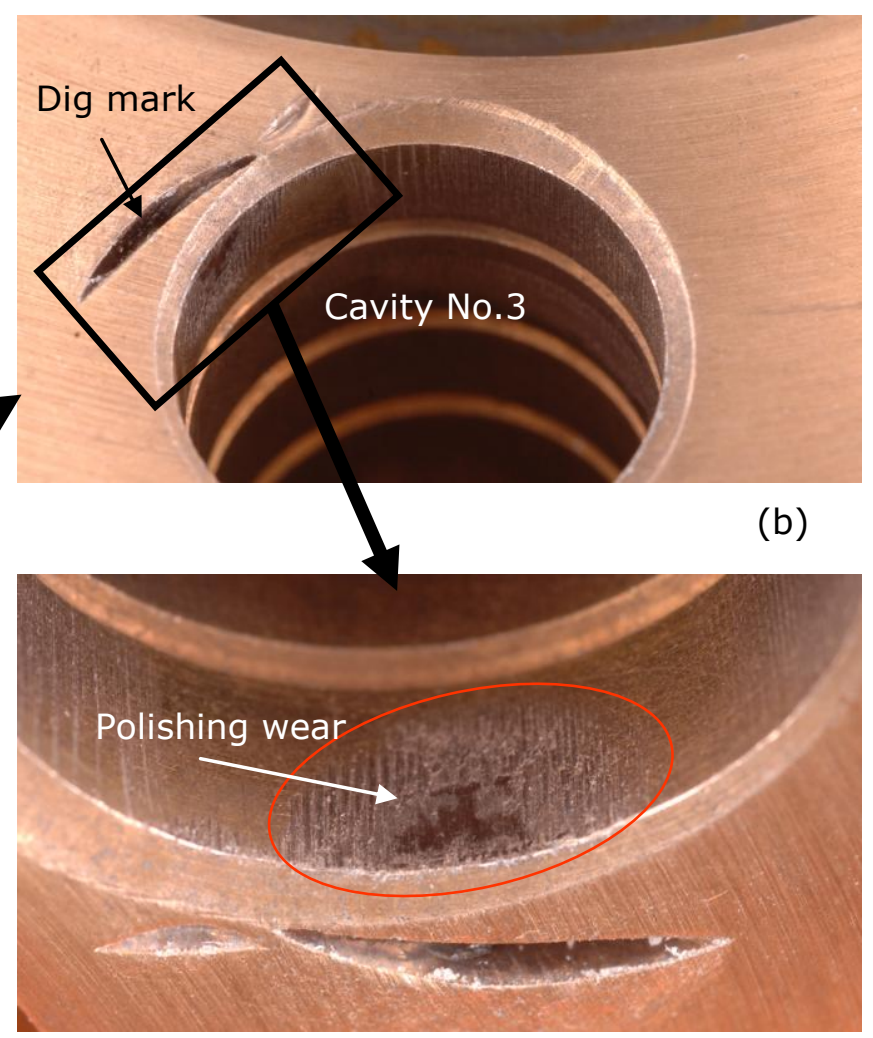

(c)

Figure 2: (a) Rotor of the MFP; cavity No. indicated, (b) dig mark resembling an arc on the surface facing the swash plate, and (c) polishing wear on the inner surface of the cavity No.3

\subsection{Body casing}

Figure 3(a) shows the body casing of the MFP. It was found to be in tact except for the damages on the inner surface over a circumferential band (Fig.3(b)). Similar damages were observed on the corresponding location on the conical surface of the rotor (Fig.2(a) and Fig.3(c)). It can be seen that the damages were caused due to churning of hard debris during rotation of the rotor. Numerous dig marks, resembling the shape of arcs, indicated that at least one fragment in the debris was sufficiently large. The fragment was part of a curved surface with circular cross section and it appeared to be the fractured part of the plunger No.3, which was recovered from the body casing of the MFP during dis-assembly. 


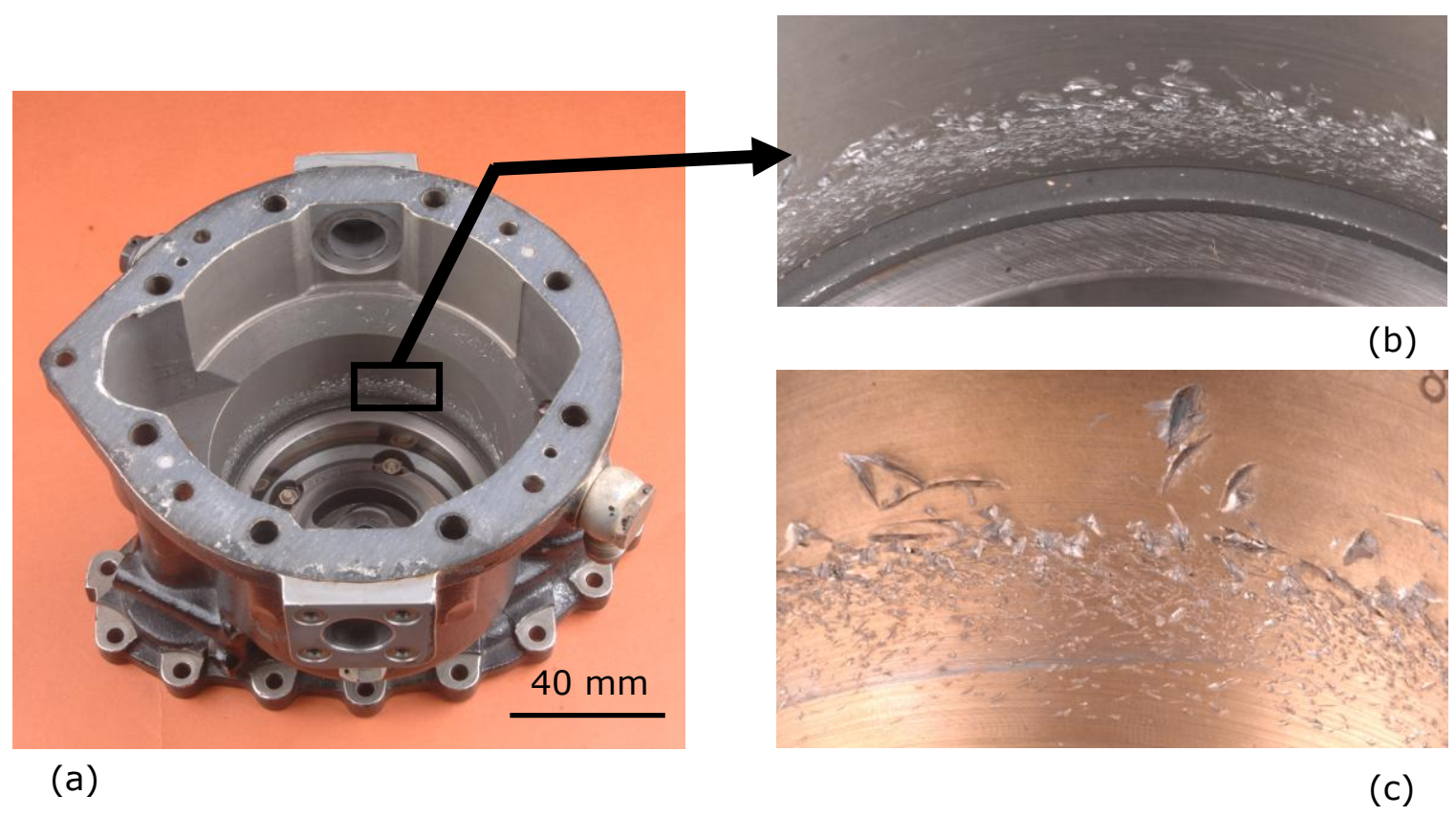

Figure 3: (a) Body casing of MFP, (b) damages on the inner surface of the casing, and (c) damages on the outer conical surface of the rotor in the corresponding region

\subsection{Plungers}

One of the nine plungers of the MFP was found to have a hole on the side wall due to loss of material by fracture (refer Fig.4). This plunger was located in the cavity No.3 of the rotor. A fragment, approximately of circular shape and having a diameter of about $9 \mathrm{~mm}$, got separated from the plunger side wall at a location close to the crown (Fig.5). The fracture surface on this fragment was found damaged and it was smeared with material rich in $\mathrm{Cu}$ and $\mathrm{Al}$, picked up from the rotor (made of Cu-alloy) and the body casing (made of Al-alloy).

Examination of the plunger No.3 showed presence of beach marks or crack arrest marks on the fracture surface, indicative of progressive mode of crack propagation (Fig.6). From the orientation of the beach marks, the fatigue crack initiation site was identified at the region marked 'B' in Fig.6(c). After initiation, the fatigue crack had propagated progressively over the region BCDE before giving way to final overload fracture (region EA in Fig.6(c)) resulting in dislodgement of a fragment from the plunger side wall. The gross fractographic features in the region $A B$ indicated that this surface was created by fast fracture. Examination also revealed that the fracture surface $A B$ was the extension of a through thickness longitudinal crack that was present over the entire length of the plunger (Fig.6(b,d)). 


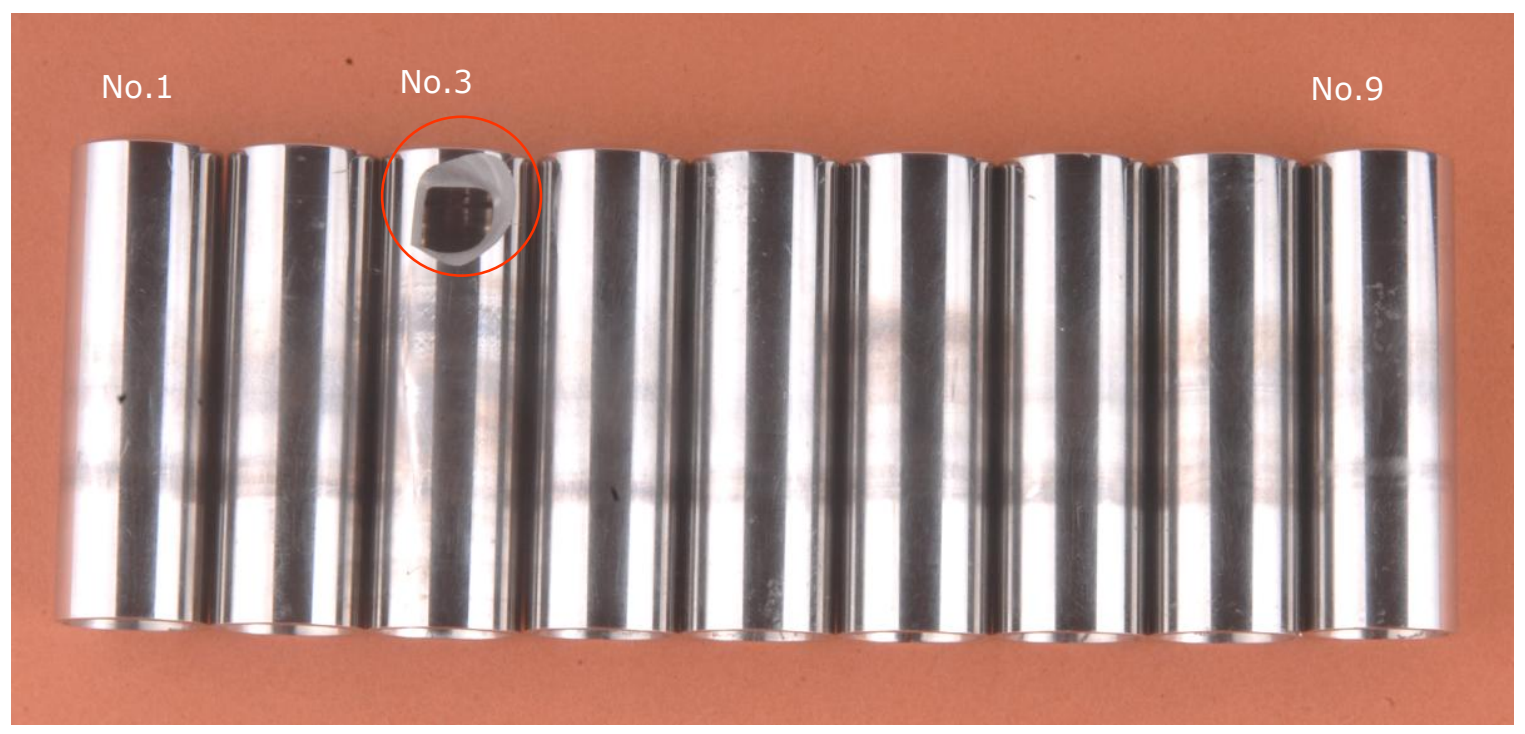

Figure 4: Nine plungers of the main fuel pump and fracture in the side wall of plunger No.3

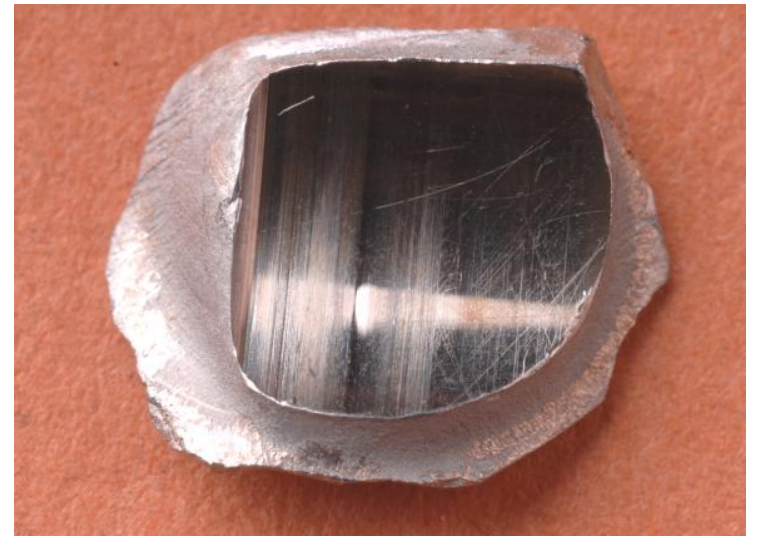

(a)

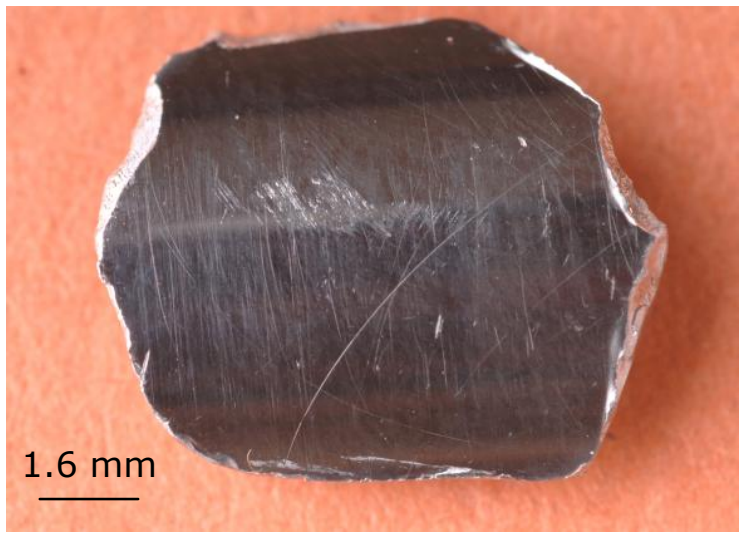

(b)

Figure 5: Fractured and dislodged part of MFP plunger No.3: (a) inner surface, and (b) outer surface

Suitable cut was provided in the plunger and the longitudinal crack surface was opened for further study (Fig.7). Examination revealed that the longitudinal crack on the plunger had three distinct zones, two fast fracture regions separated by a region of fatigue fracture (Fig.7(b)). Based on the orientation of the crack arrest marks, the crack initiation region and the crack propagation direction were identified, and these are shown in Fig.7(f).

The modes of crack propagation at different regions on the plunger were confirmed through scanning electron fractographic study. Fatigue striations and dimples were seen on the progressive crack propagation zones and fast fracture regions, respectively (Fig.8). 

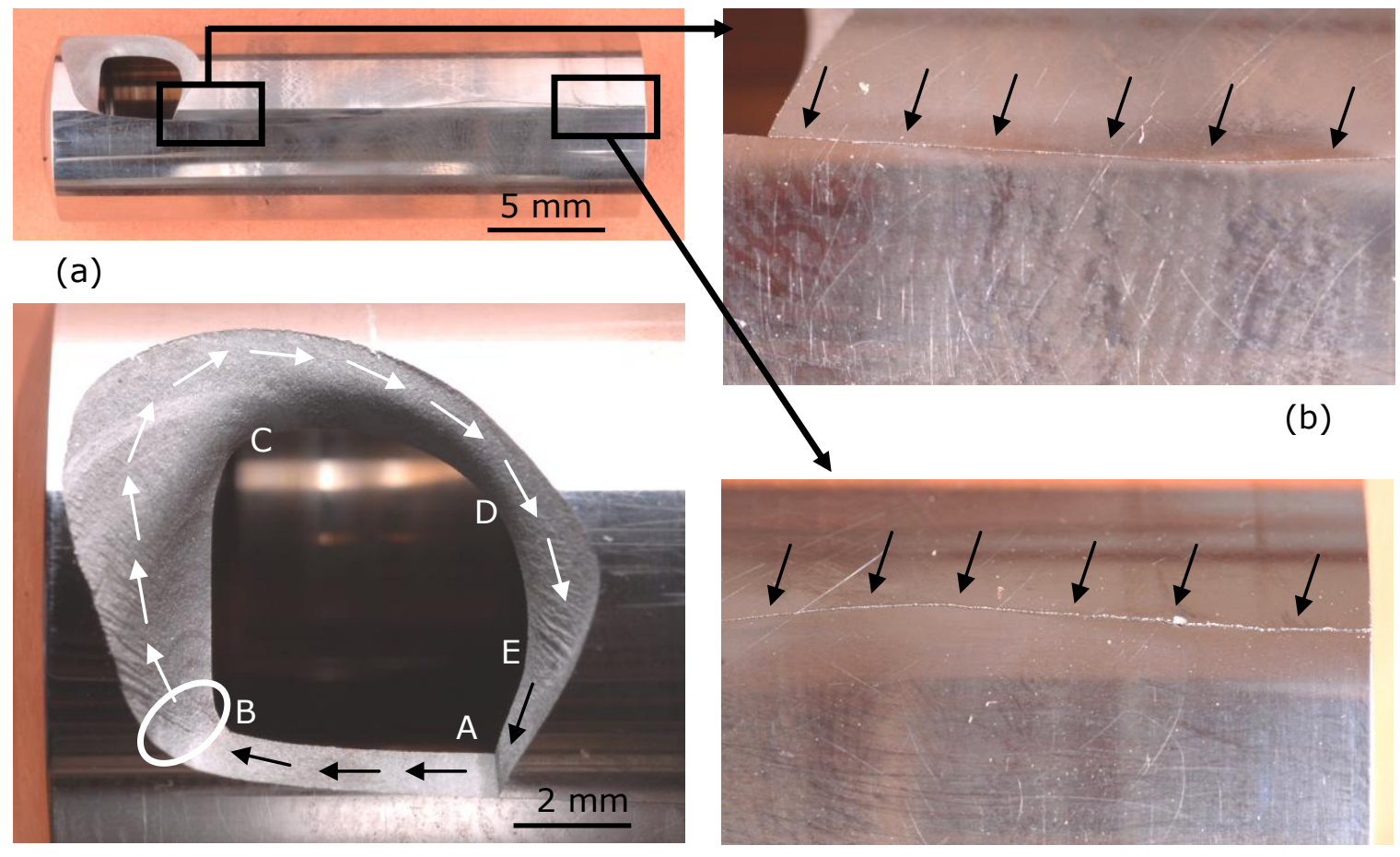

(c)

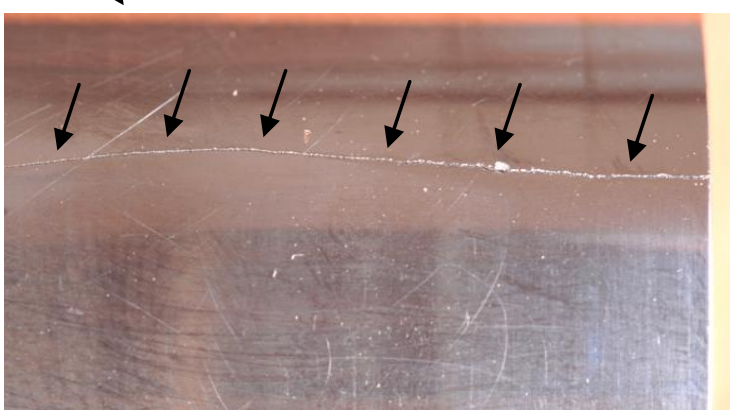

(d)

Figure 6: (a) Plunger No.3, (b) crack along the longitudinal direction (black arrows), (c) fracture surface showing fatigue crack origin, encircled (B), progressive crack propagation direction over region $B C D E$ (white arrows) and overload fracture in regions $E A$ and $A B$ (black arrows), and (d) extension of the crack shown in (b) up to the bottom edge of the plunger

Fractographic study suggested that there was generation of an overload crack at the bottom edge of the plunger, which subsequently propagated by fatigue mechanism. Examination of this region showed impact damages on the tapered inner surface (Fig.9(a)). These damages were observed only on the plunger No.3 and the other eight plungers were found free from any such damages (Fig.9(b)).

Observations did not reveal any distress on the outer surface of the plungers. There were no wear tracks in the longitudinal direction of the surface and hence, possibility of fuel contamination with hard particles was ruled out. The wear on the crown surface of the plungers was also found to be minimal and normal. Minor polishing marks were noticed on the surface of all the plungers at the mid-length region covering about one-third of the length. Such polishing wear is normal and generally occurs due to rotation of the plungers during pump operation.

The material of construction of the plunger was evaluated and it conformed to the specification in respect of chemical composition (Table 1 ), microstructure (Fig.10) and hardness (62 HRC). 


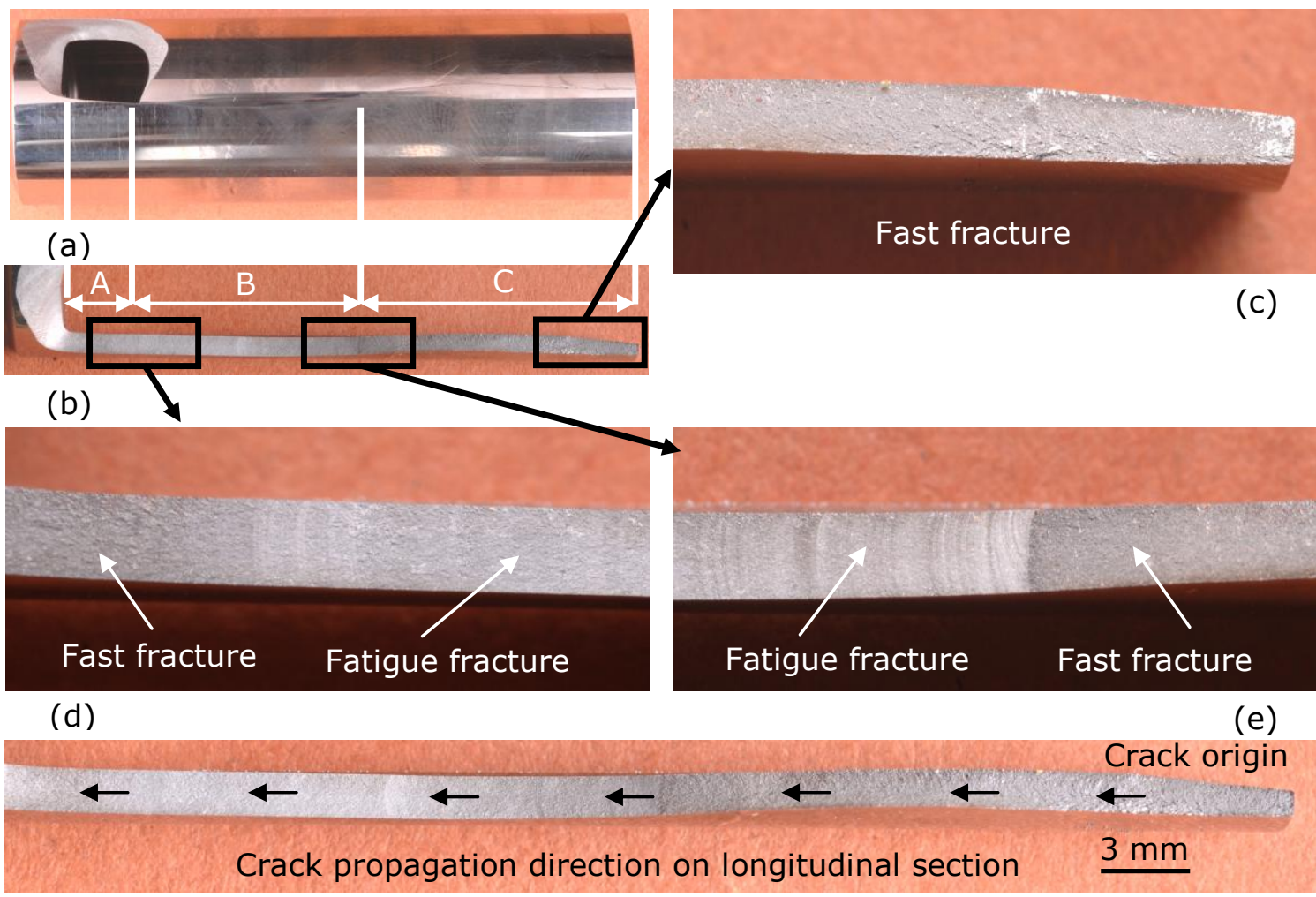

(f)

Figure 7: (a-b) Three distinct fracture regions along the longitudinal crack on plunger No.3, (c) fast fracture in region $C_{1}$ (d) transition of fatigue to fast mode of crack propagation from region $B$ to $A,(e)$ transition from fast fracture to fatigue mode of crack propagation from region $C$ to $B$, and ( $f$ ) crack initiation and propagation along the longitudinal direction

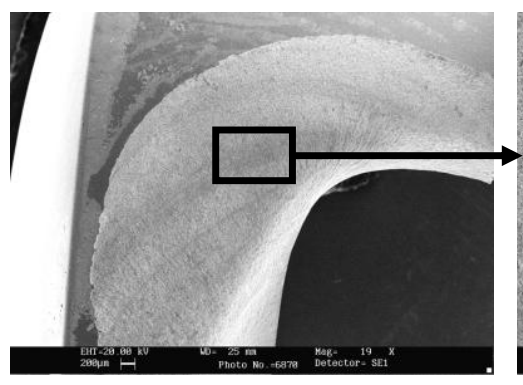

(a)

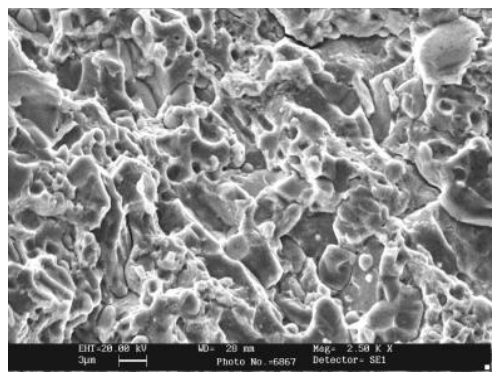

(d)

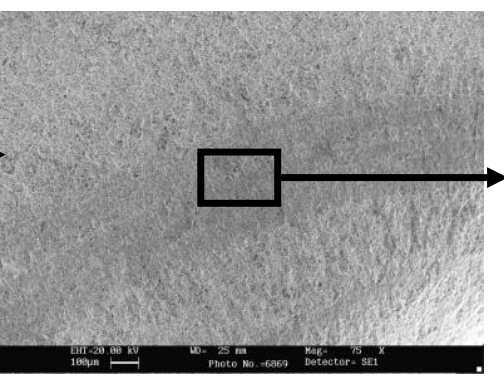

(b)

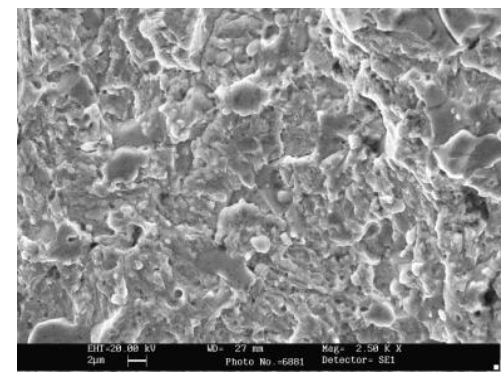

(e)

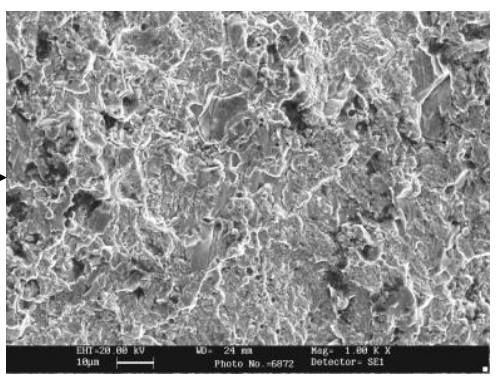

(c)

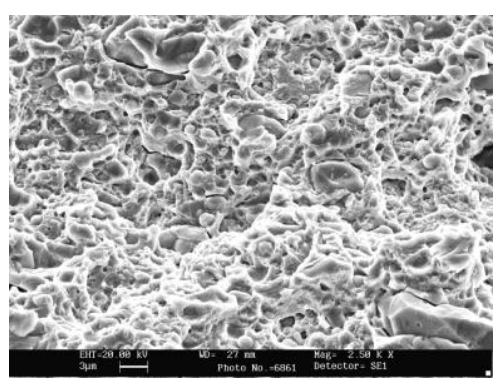

(f)

Figure 8: Scanning electron fractographs: $(a-c)$ fatigue mode of crack propagation in region $B C D E$ marked in Fig. 6(c), and (d) fast fracture, (e) fatigue fracture, and (f) fast fracture in regions $A, B$ and $C$ respectively marked in Fig. $7(b)$ 


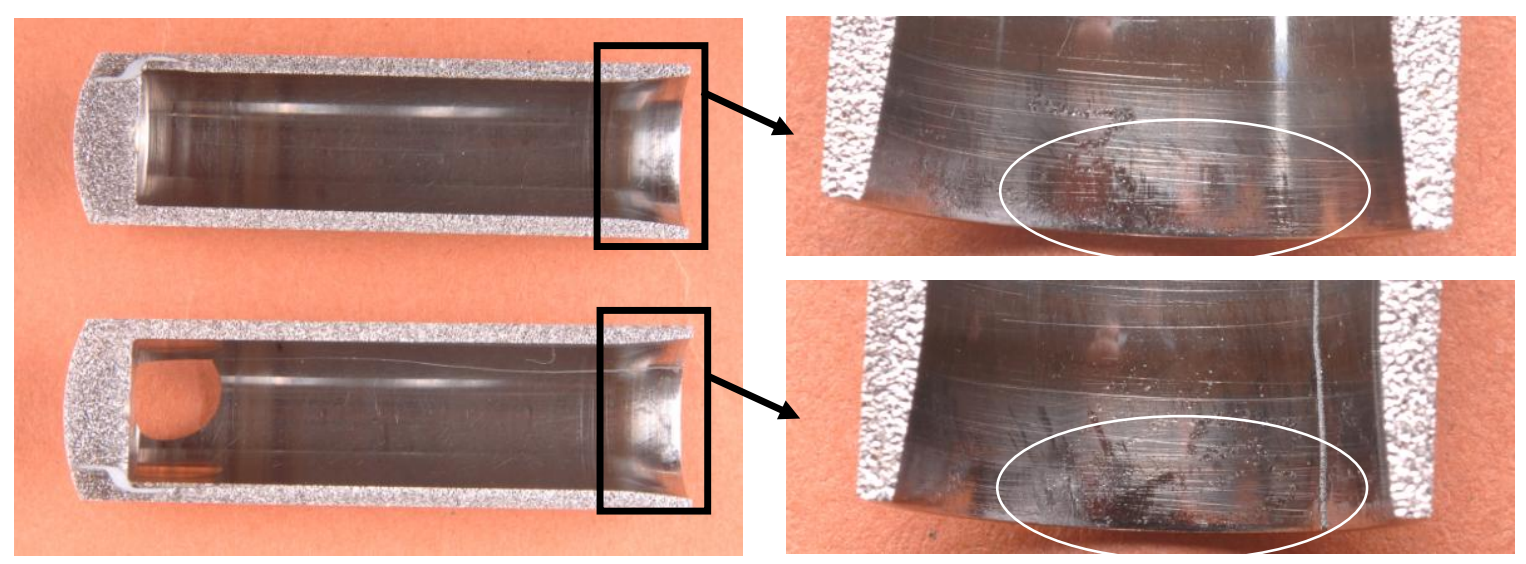

(a)

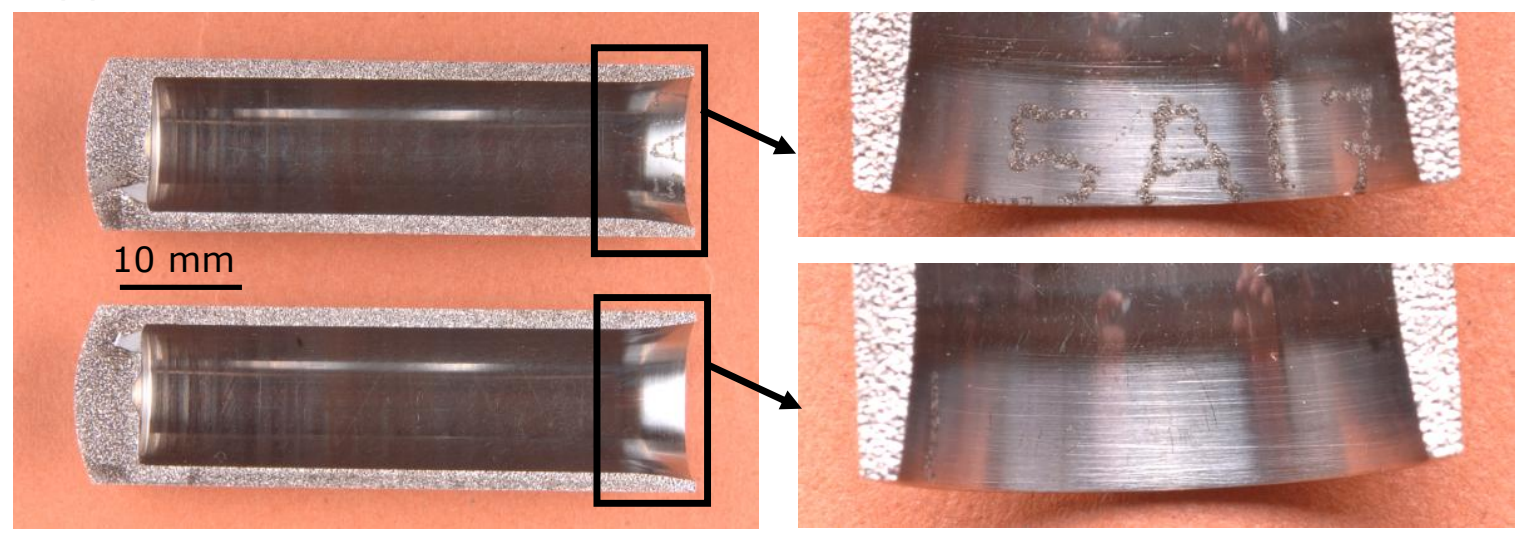

(b)

Figure 9: Inner surface of (a) plunger No.3, and (b) plunger No.1; damages on the taper surface of plunger No.3 encircled

Table 1: Chemical compositional of plunger material; carried out by optical emission spectroscopy

\begin{tabular}{llr}
\hline Composition, wt\% & & \\
\hline Element & Specification & Plunger No.3 \\
\hline $\mathrm{C}$ & $1.45-1.65$ & 1.58 \\
$\mathrm{Mn}$ & $0.15-0.40$ & 0.27 \\
$\mathrm{Si}$ & $0.15-0.35$ & 0.31 \\
$\mathrm{Cr}$ & $11.00-12.50$ & 11.35 \\
$\mathrm{Mo}$ & $0.40-0.60$ & 0.49 \\
$\mathrm{~V}$ & $0.15-0.30$ & 0.26 \\
$\mathrm{Fe}$ & Balance & Balance \\
\hline
\end{tabular}

\subsection{Springs}

The springs of the plunger Nos. 3, 4, 6 and 7 were found fractured. Spring No. 3 had fractured into four pieces, while the other three springs had fractured into two pieces each (Fig.11). 


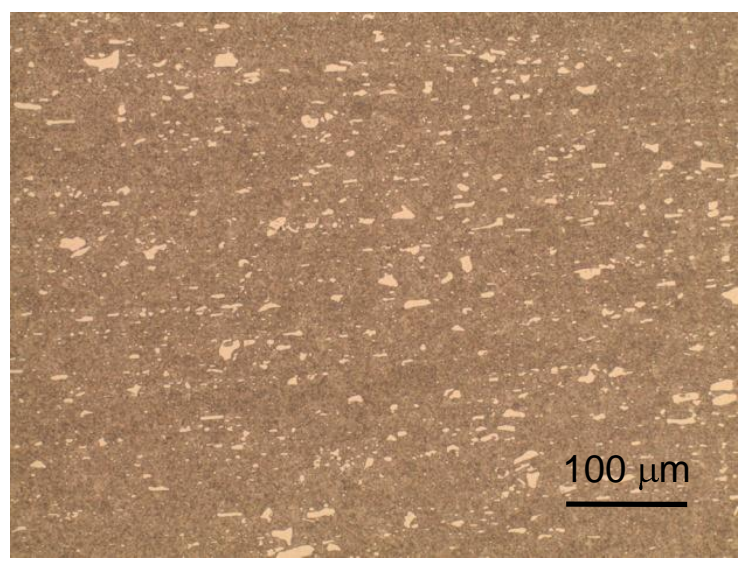

(a)

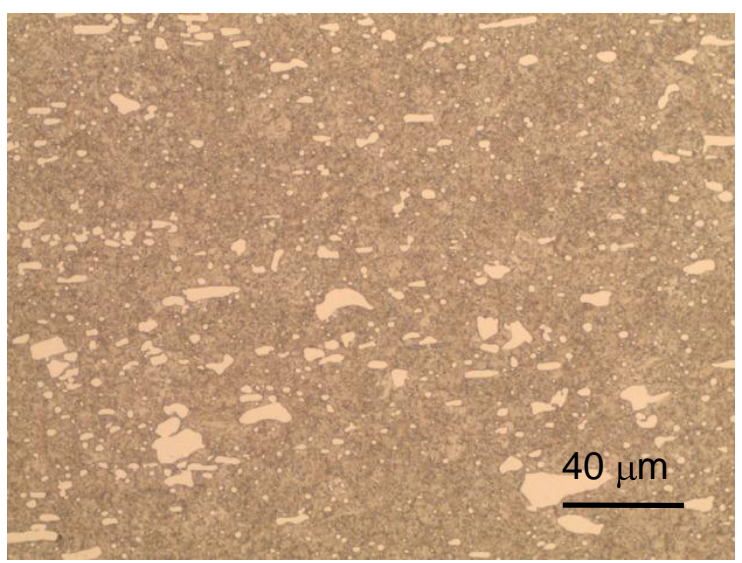

(b)

Figure 10: Optical microstructures of the plunger material showing satisfactory tempered martensitic structure dispersed with carbide particles: (a) longitudinal section, and (b) cross section (etched with $2 \%$ Nital solution)

The four fractured parts of the spring No. 3 are shown in Fig.12. The fractured part B was found entangled in the fractured part $\mathrm{C}$. Examination of the faces of each of the fractured parts of the spring showed that the faces corresponding to fracture 1 had deformed/flattened to a large extent. The damages on the faces of the other fractured parts were found to be relatively less. This indicates that fracture 1 was the first in the sequence of occurrence, followed by which the other two fractures had occurred.

The spring ends corresponding to the fracture 1 were found damaged/ rubbed substantially resulting in complete obliteration of the fractographic features. The other fracture ends of the spring were found relatively preserved. These fractures were found to be oriented approximately at $45^{\circ}$ with the wire axis of the spring. Examination revealed that the fracture surfaces were flat and smooth in appearance, indicative of progressive mode of crack propagation.

Figures 13 and 14 show the scanning electron fractographs of the broken ends corresponding to the fractures 2 and 3 respectively. The fracture surfaces showed clearly delineated half-moon shaped region consisting of beach marks or crack arrest marks, typical of fatigue mode of crack propagation. From the orientation of the beach marks, the fatigue crack origins were identified and they were found to be corrosion pits on the spring surface. Further examination showed presence of numerous corrosion pits on the surface of the spring (Fig.15). Compositional analysis showed that corrosion products in these pits contained corrosion species such as chlorine (Table 2). 


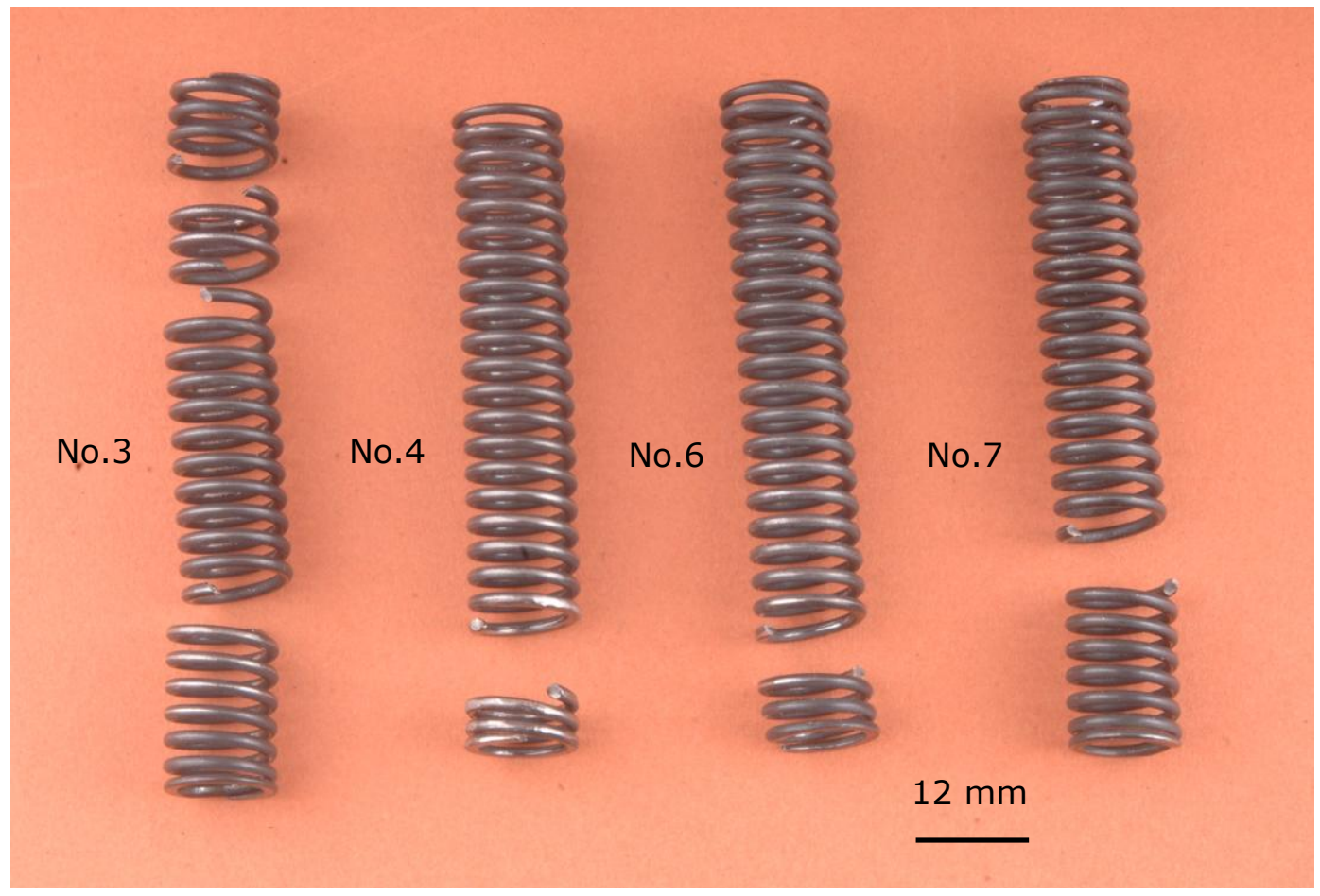

Figure 11: Fractured springs of the MFP; the locations of the springs in the corresponding plungers indicated

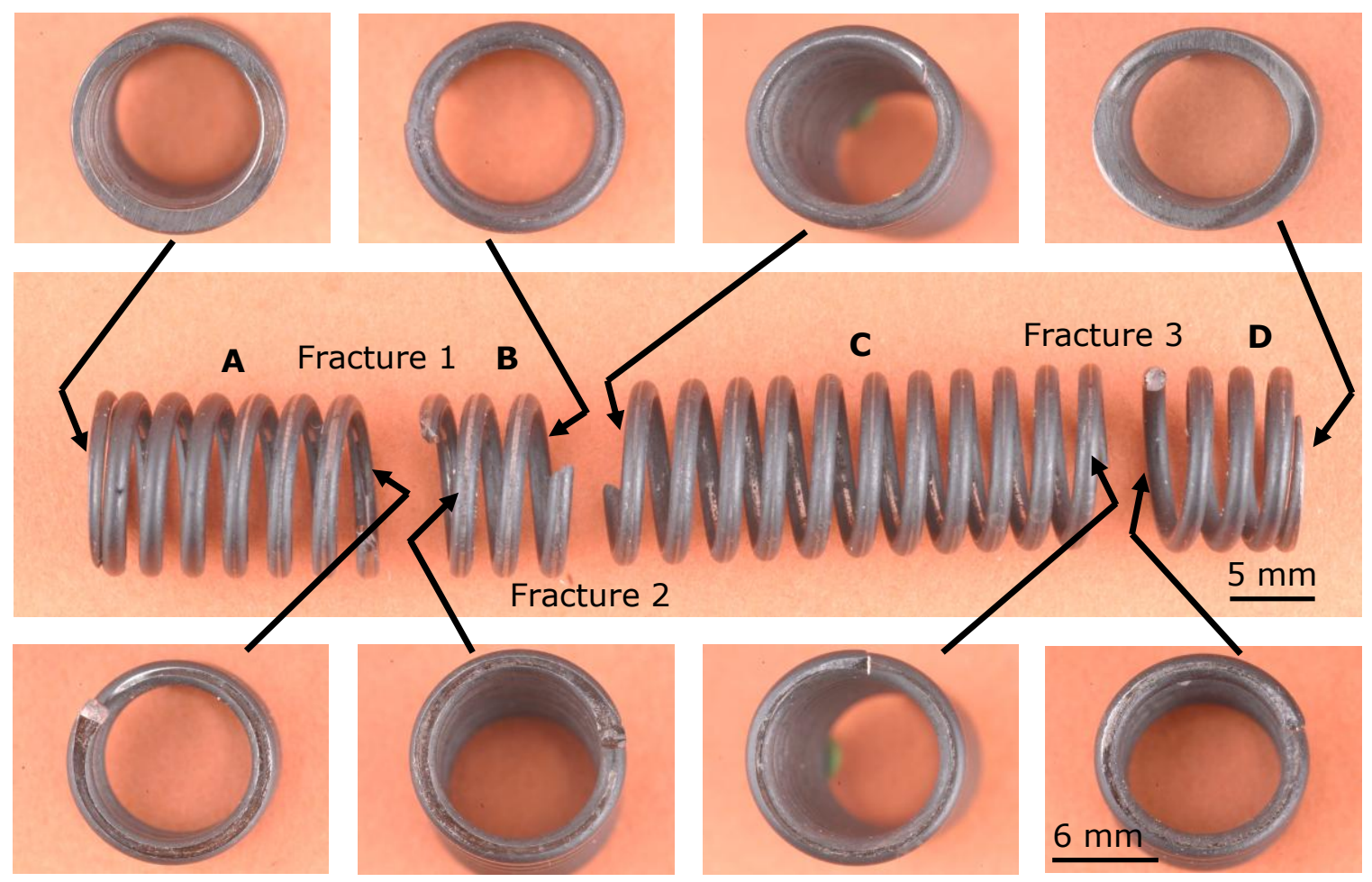

Figure 12: Fractures in spring No.3 showing relative damages on the faces of the broken parts 


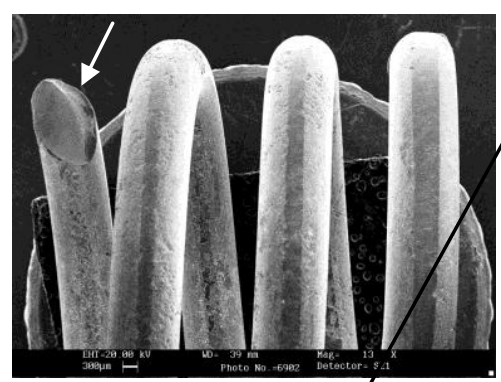

(a)

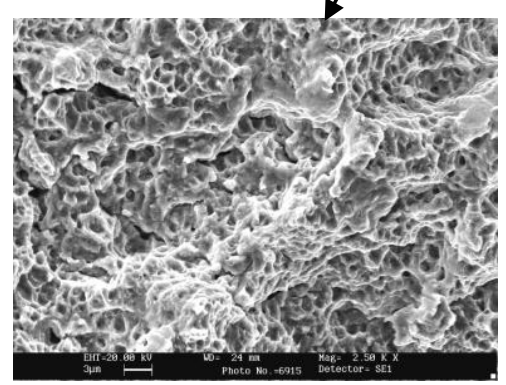

(d)

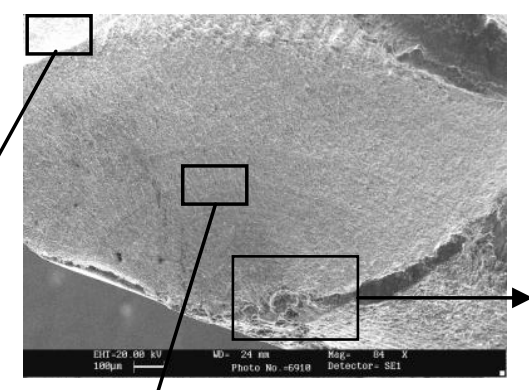

(b)

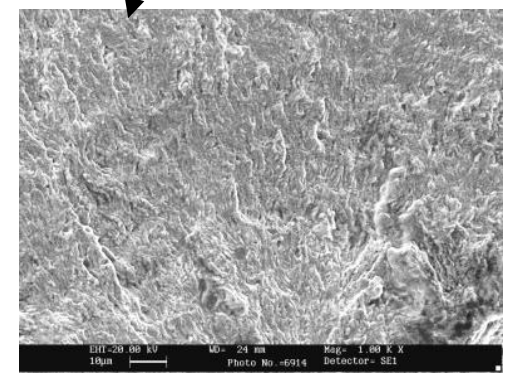

(e)

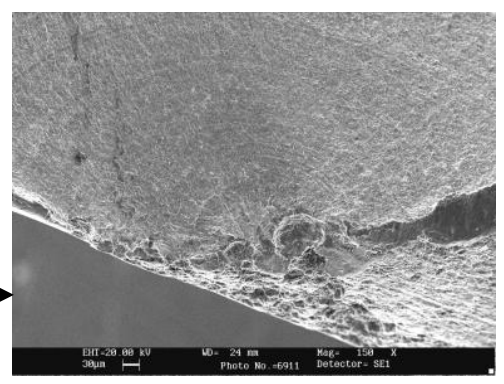

(c)

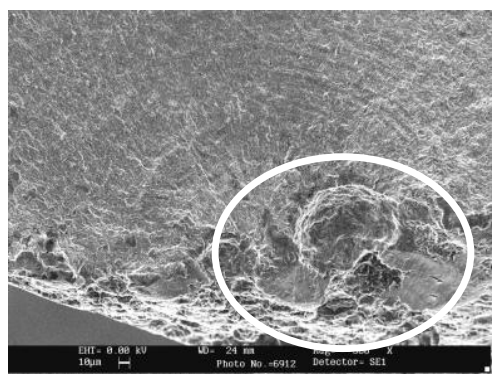

(f)

Figure 13: Scanning electron fractographs of one of the mating surfaces of fracture 2 of spring No.3: (a) fracture surface oriented approximately $45^{\circ}$ with the wire axis (arrow), (b) crack arrest marks or beach marks, (c) fatigue crack origin region, (d) dimple rupture, (e) fatigue striations, and (f) corrosion pits at the fatigue crack origin (encircled)

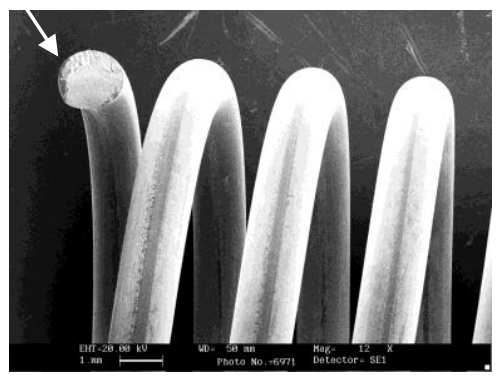

(a)

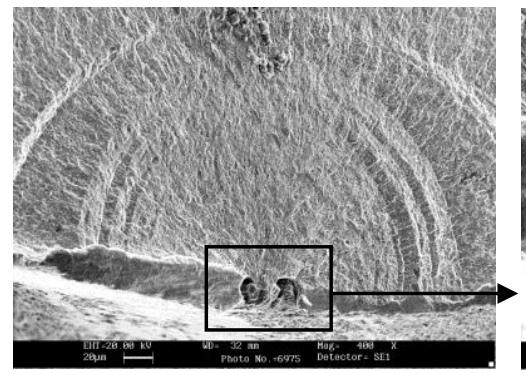

(d)

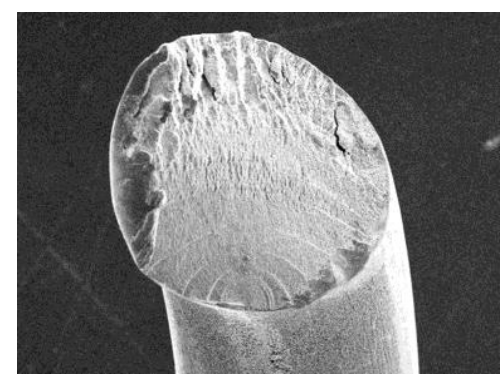

(b)

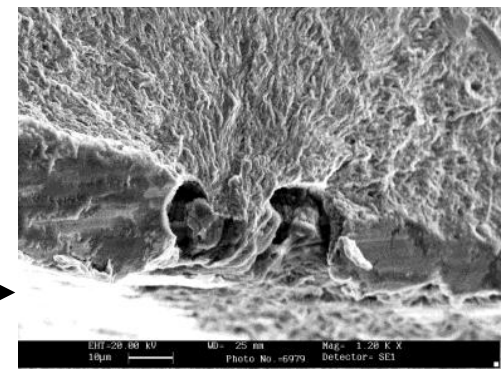

(e)

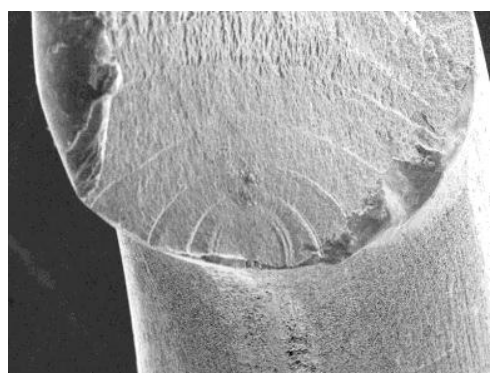

(c)

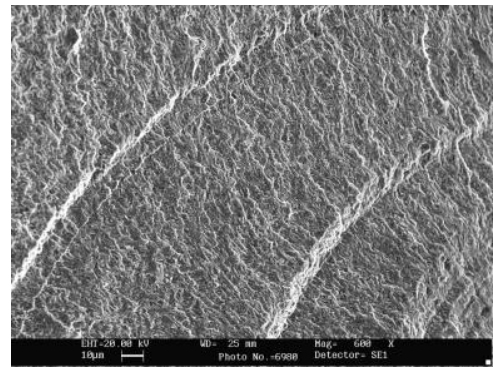

(f)

Figure 14: Scanning electron fractographs of one of the mating surfaces of fracture 3 of spring No.3: (a) fracture surface oriented approximately $45^{\circ}$ with the wire axis (arrow), (b) crack arrest marks or beach marks, (c) magnified view showing concentric crack arrest marks, (d) fatigue crack origin (rectangular box), (e) corrosion pits at the fatigue crack origin, and (f) fatigue striations 
Fractographic study confirmed that the fractures in springs 4, 6 and 7 were also by fatigue mechanism. The crack origin regions in these springs were largely damaged and hence, no further study could be conducted. However, corrosion pits were observed on the surfaces of these springs as well (Fig.16 and Table 2).

The material of construction of the springs conformed to the specification in terms of chemical composition (Table 3), microstructure (Fig.17), and hardness (50-52 HRC).

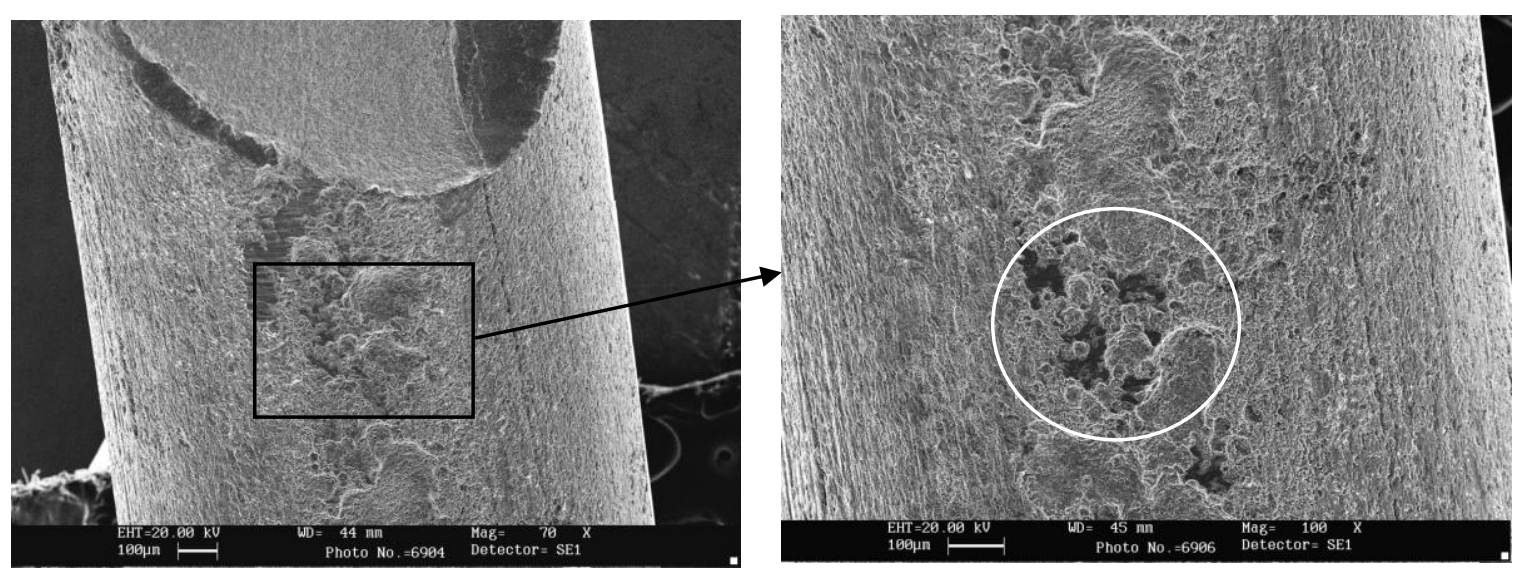

(a)

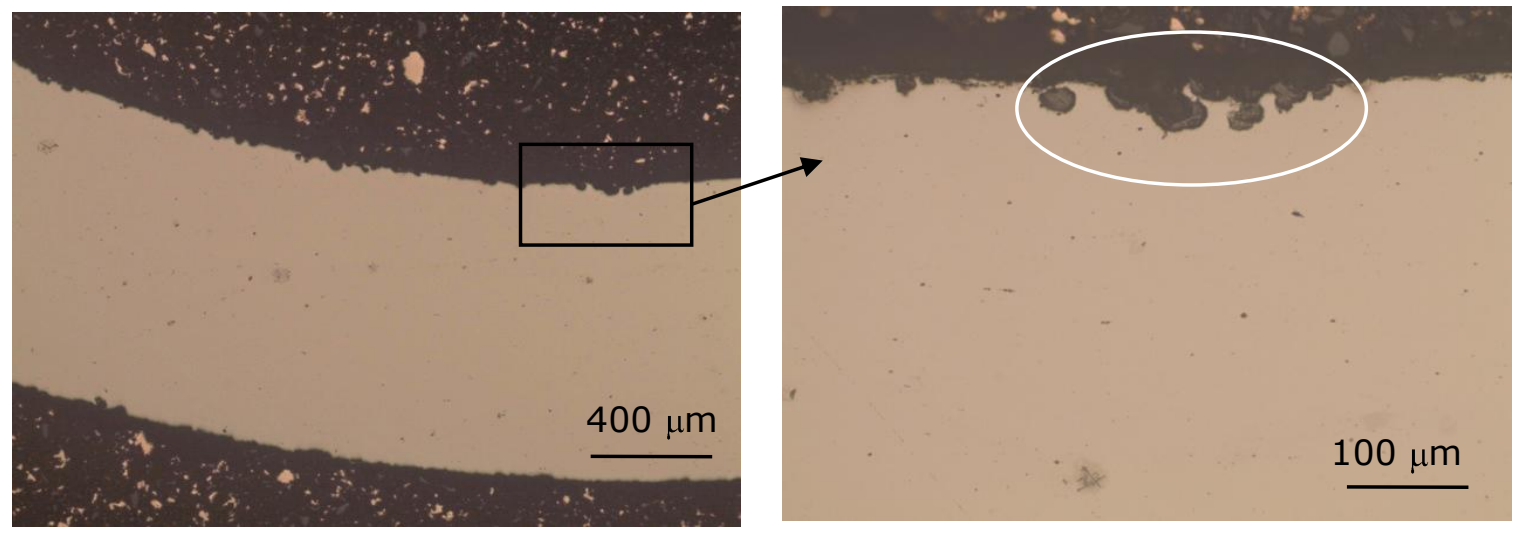

(b)

Figure 15: (a) Scanning electron images of the surface of the broken spring No.3 showing corrosion pits, and (b) optical micrographs of the longitudinal section of the spring wire showing corrosion on the surface (encircled)

\subsection{Analysis of fuel samples}

Fuel samples were collected from the main fuel pump and the fuel oil unit and they were subjected to evaluation. Analysis showed that the fuel quality conformed to the specification and did not contain chlorine. The sulphur content was within permissible limit. 


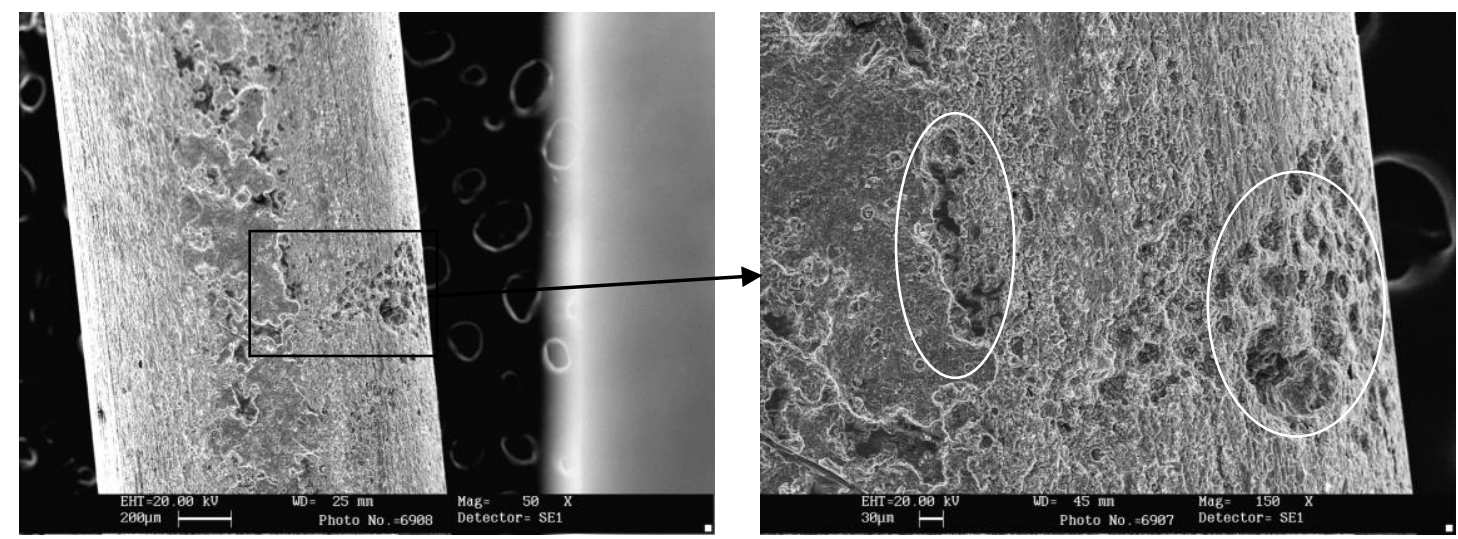

Figure 16: Scanning electron images of the surface of the broken spring No.6 showing corrosion pits (encircled)

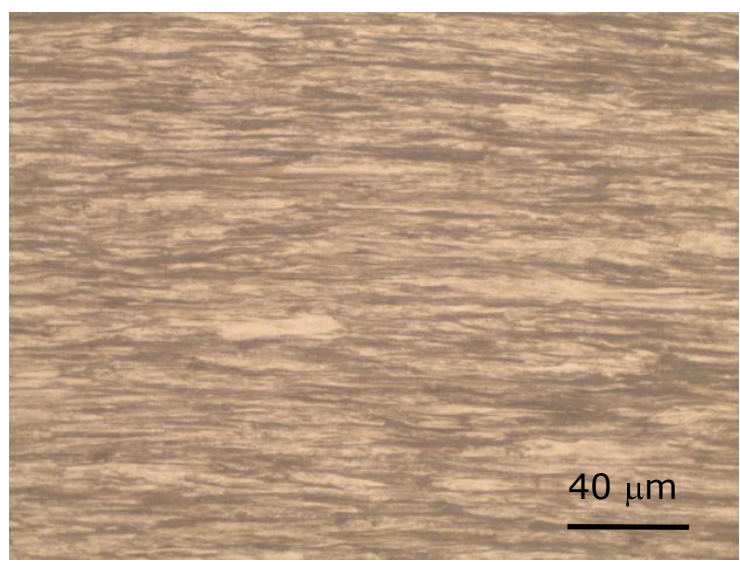

(a)

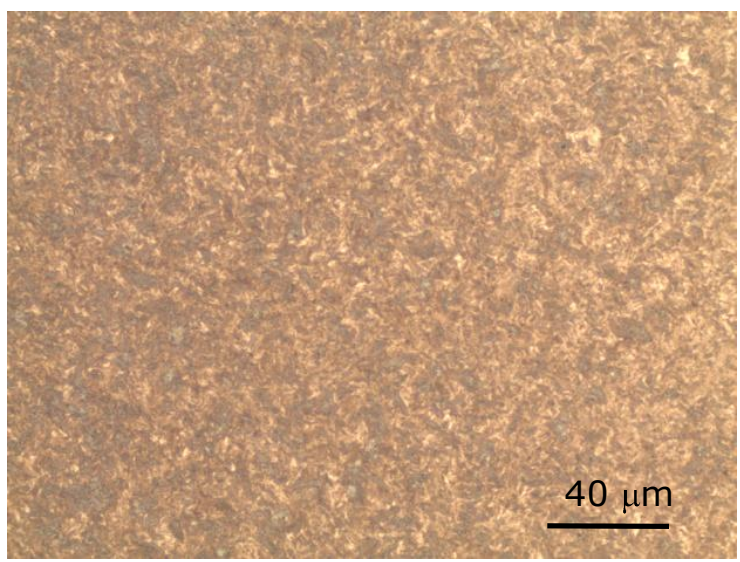

(b)

Figure 17: Optical microstructures of No.3 spring of the fuel pump showing satisfactory tempered martensitic structure: (a) longitudinal section, typical of cold drawn wire, and (b) cross section (etched with $2 \%$ Nital solution)

\subsection{Raw material of springs and unused springs}

The raw material wire and the unused springs from the same batch of production as the fractured ones were evaluated. Examination revealed corrosion on the surfaces of the raw material as well as the springs (Fig.18). Compositional analysis showed presence of chlorine in the corrosion products (Table 2). 


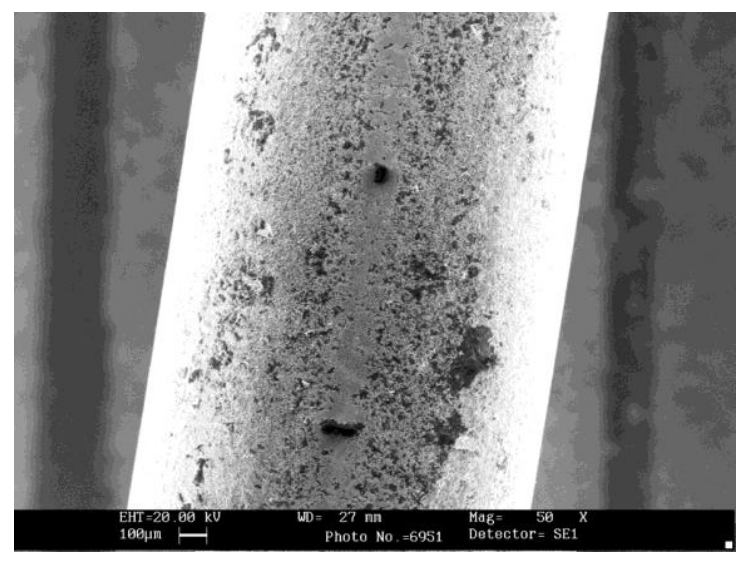

(a)

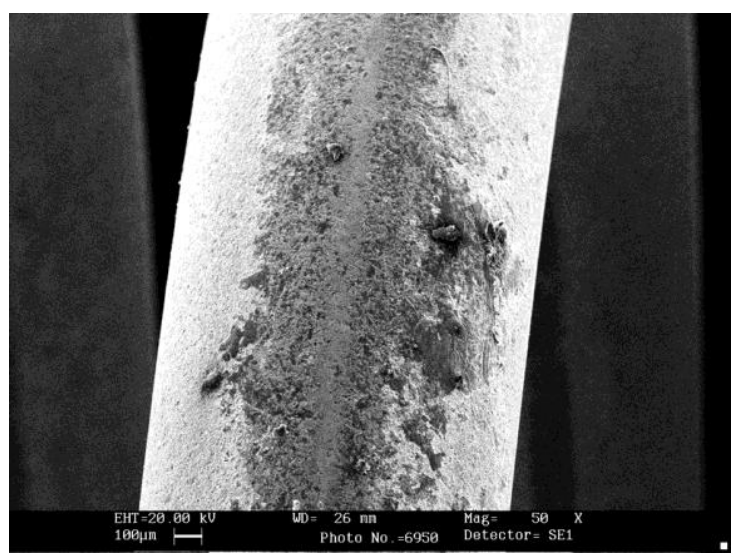

(b)

Figure 18: Scanning electron images showing corrosion on the surfaces of the (a) raw material wire, and (b) an unused spring

Table 2: Semi-quantitative composition analysis of the corrosion products; carried out by energy dispersive X-ray analysis

\begin{tabular}{lcclccc}
\hline \multirow{2}{*}{ Element } & \multicolumn{7}{c}{ Composition, wt\% } \\
\cline { 2 - 6 } & \multicolumn{2}{c}{ Fatigue crack origins } & \multicolumn{3}{c}{ Spring surface } & Raw material \\
\cline { 1 - 5 } & Fig.13(f) & Fig.14(e) & Fig.15(a) & Fig.16 & Fig.18(b) & (Fig. 18(a)) \\
\hline $\mathrm{O}$ & 38.4 & 26.8 & 21.4 & 27.7 & 33.7 & 26.9 \\
$\mathrm{Al}$ & 0.6 & 0.1 & 0.8 & 0.5 & 0.8 & 0.6 \\
$\mathrm{Si}$ & 1.1 & 0.4 & 0.9 & 0.6 & 0.9 & 0.5 \\
$\mathrm{Cl}$ & 0.3 & 0.6 & 0.2 & 0.3 & 0.6 & 0.4 \\
$\mathrm{Ti}$ & 0.8 & 0.3 & 0.2 & 0.3 & 0.2 & 0.2 \\
$\mathrm{Cr}$ & 0.2 & 3.0 & 0.3 & 0.2 & 0.3 & 0.3 \\
$\mathrm{Mn}$ & 0.8 & 0.9 & 1.3 & 1.2 & 1.5 & 1.1 \\
$\mathrm{Fe}$ & Balance & Balance & Balance & Balance & Balance & Balance \\
\hline
\end{tabular}

Table 3: Chemical composition of spring material; carried out by optical emission spectroscopy

\begin{tabular}{lllcccr}
\hline \multicolumn{2}{l}{ Composition, wt\% } & \multicolumn{5}{c}{ Springs of MFP } \\
\hline \multirow{2}{*}{ Element } & \multirow{2}{*}{ Specification } & \multicolumn{5}{c}{ } \\
\cline { 3 - 7 } & & Unused & 3 & 4 & 6 & 7 \\
\hline $\mathrm{C}$ & $0.47-0.55$ & 0.49 & 0.52 & 0.50 & 0.54 & 0.48 \\
$\mathrm{Si}$ & $0.15-0.30$ & 0.31 & 0.33 & 0.30 & 0.29 & 0.27 \\
$\mathrm{Mn}$ & $0.3-0.6$ & 0.54 & 0.58 & 0.48 & 0.47 & 0.51 \\
$\mathrm{Cr}$ & $0.75-1.1$ & 0.98 & 1.11 & 0.89 & 1.06 & 1.01 \\
$\mathrm{~V}$ & $0.15-0.25$ & 0.21 & 0.23 & 0.19 & 0.18 & 0.28 \\
$\mathrm{Ni}$ & $\leq 0.3$ & 0.23 & 0.20 & 0.17 & 0.27 & 0.28 \\
$\mathrm{Fe}$ & Balance & Balance & Balance & Balance & Balance & Balance \\
\hline
\end{tabular}




\section{Analysis}

\subsection{Failure in the engine}

Fractographic study confirmed that plunger No.3 of MFP has failed in progressive manner leading to dislodgement of a piece of material from the side wall of the plunger close to the crown. The resultant hole in the plunger was responsible for fuel leakage internally in the MFP, which in turn prevented generation of fuel pressure to the required level. As a consequence, there was less fuel delivery to the engine leading to winding down of engine RPM and subsequent accident.

\subsection{Failure in the MFP}

It has been established through fractographic study that the fatigue failure in plunger No.3 was promoted due to generation of an overload crack in the longitudinal direction over a length of about $22 \mathrm{~mm}$ from the bottom edge. Such longitudinal cracking of the plunger due to hoop-stress is unlikely under the operating fuel pressure. It, therefore, appears that there was abnormal loading on the edge of the plunger through the spring and the guide located inside.

Examination of the inner surface of the plunger at the overload crack origin region showed distress in the form of rubbing with the spring. The rubbing took place in regions where the inner surface of the plunger surface is tapered outward. The rubbing marks were found to be unique to plunger No. 3 and the other plungers were found to be free from such damages. It is to be noted that the spring of the plunger No.3 had broken into four pieces. Therefore, the contact of the spring with the tapered surface of the plunger was possible because of this breakage.

Laboratory investigation showed that all the fractures in spring No.3 were by fatigue mechanism. It was also established that the premature fatigue fracture of the spring was promoted due to corrosion on the spring surface.

In the sequence of failure, the spring No.3 had fractured by fatigue leading to a situation wherein the parts of the spring were either misaligned or telescoped in. This had resulted in impact load on the plunger at the bottom edge leading to generation of an overload crack of length $22 \mathrm{~mm}$. This crack had then propagated further by fatigue over a length of about $20 \mathrm{~mm}$. Followed by which, the crack had again propagated by overload and got arrested at the top inner surface of the plunger. The crack edge at the top 
surface had then propagated by fatigue following roughly a circular path leading to dislodgement of material from a sector of the side wall of the plunger. Following this, the dislodged fragment had fallen in the annular space between the rotor and the pump body casing. The churning of this fragment during operation of the pump had damaged the outer conical surface of the rotor and the inner surface of the pump body casing over a circular band.

Therefore, the primary reason for the failure of plunger No.3 of the MFP was the fatigue fracture of the spring. The fatigue fracture of the spring was promoted due to corrosion. The failure of the springs 4,6 and 7 was also by fatigue because of the same reason. Evidences suggest that the failure in spring 3 was the first among the four spring failures. Also, failures in the four springs were independent of each other and had occurred at different times.

Metallurgical evaluation of the plunger and spring materials showed that they conformed to their respective specifications. Hence, no deficiency in the material of construction was responsible for the fatigue crack initiation. The results of the fuel analysis suggested that there was no contamination which could result in corrosion on the surface of the MFP springs.

\subsection{Primary cause of failure}

Follow-up investigation revealed corrosion on the surface of the raw material wire that was used for the fabrication of the springs. Same observations were also made on the surface of the springs belonging to the same batch of production. On examination of the records, it was found that the raw material wires were procured at least 12-15 years ago, and they were kept in bonded stores without proper surface protection. The interaction of the virgin material with the atmosphere for a prolonged period was responsible for the development of corrosion pits on the surface of the wires. The same defects got carried forward when the springs were fabricated from these wires. Therefore, the primary reason for the failure was the improper storage of raw material wires used for the fabrication of MFP springs.

\section{Conclusions}

(a) Investigation showed that the winding down of the engine RPM was due to failure in the MFP. The failure was progressive in nature. 
(b) Four springs in the MFP had failed by fatigue. The premature fatigue failure in these springs was promoted due to corrosion on the springs' surface. The failure of spring No.3 had resulted in progressive failure of the corresponding plunger leading to separation of a piece from the side wall of the plunger. As a result, there was fuel leakage internally in the MFP. This in turn, prevented generation of fuel pressure to the required level with the consequence of less fuel delivery to the engine.

(c) The corrosion pits on the springs of the MFP were not developed during usage. Instead, it was carried forward from the raw material stage. It was established that there was development of corrosion pits on the surface of the raw material wires during storage. Therefore, the primary reason for the spring failure was the improper storage of the raw material for a long period of time without proper surface protection.

\section{Recommendations}

(a) It is recommended that the springs of the production batch in question be rejected. Also, MFPs which have been assembled using springs from this batch be withdrawn from service and the springs be replaced.

(c) The surface condition of the available raw material must be evaluated. In case corrosion pits are observed, the wires must be rejected.

(b) Appropriate procedure should be followed for surface protection of the raw material wire as well as the manufactured springs that are kept in the bonded stores.

\section{Acknowledgements}

The authors thank Ms. Kalavati for assistance in fractography.

\section{References}

[1] Daniel P. Dennies, How to Organize and Run a Failure Investigation. ASM International, American Society for Metals, Metals park, Ohio, (2005).

[2] V. Ramachandran, A.C. Raghuram, R.V. Krishnan, S.K. Bhaumik, Failure Analysis of Engineering Structures: Methodologies and Case Histories. ASM International, Materials Park, Ohio (2005). 
[3] S.J. Findlay and N.D. Harrison, Why aircraft fail? Materials today 11 (2002) 18-25.

[4] Metals Handbook. vol.10: Failure Analysis and Prevention, $8^{\text {th }}$ ed. American Society for Metals, Metals Park, Ohio (1975).

[5] S.K. Bhaumik, M. Sujata and M.A. Venkataswamy, Fatigue failure of aircraft components. Eng. Fail. Anal. 15 (2008) 675-694 